\title{
Properties of plasters suitable for reconstruction of historical buildings
}

\author{
M. Jerman, E. Vejmelková, M. Keppert \& R. Černý \\ Department of Materials Engineering and Chemistry, \\ Faculty of Civil Engineering, Czech Technical University in Prague, \\ Czech Republic
}

\begin{abstract}
Basic physical properties, mechanical properties, hygric and thermal properties of several types of plasters which are used in the reconstruction of historical buildings in the Czech Republic, among them lime-pozzolan plasters with different pozzolans, commercial renovation renders and thermal insulation plasters, are investigated. Pure lime plaster and lime-cement plaster are studied as well, for the sake of comparison. Mechanical properties include the compressive strength and bending strength which are measured using standard methods. Orientation values of moisture diffusivity are determined using the results of water sorptivity measurements. Water vapor diffusion permeability is measured by the cup method. Sorption isotherms are determined by the desiccator method. Thermal conductivity and specific heat capacity are measured by an impulse technique.
\end{abstract}

Keywords: renovation, plasters, lime, pozzolan, properties.

\section{Introduction}

The selection of a plaster suitable for reconstruction of a historical building is mostly result of a compromise between the supervisory authorities and building owners. According to the supervisory authorities the used materials should be identical or very similar to the old materials. On the other hand, it is also important to use materials with a good durability. Sometimes, plasters with good thermal properties are required.

Historical plasters were mainly composed using three types of binders: clay, lime, and gypsum. At the end of the $19^{\text {th }}$ century, Portland cement began to be 
used with an increasing frequency. The old lime mortar composition was usually comparable with modern non-hydraulic lime mortars [1, 2]. For historical plasters it is also possible to use lime plasters improved by metakaolin. Metakaolin is a pozzolan that appears to greatly enhance properties of lime mortars [3-6].

In this paper, material properties of several types of plasters suitable for reconstruction of historical building are studied. Measured parameters can be used for determination of their service life when they are used for particular historical buildings. In the current practice, the service life of new surface layers is mostly estimated on the basis of experience because too few parameters are known for a reliable durability estimate. The choice of a material for reconstruction is then often less suitable regarding to the moisture and salt content in the masonry. Prediction of moisture and temperature fields in envelope parts of historical buildings in a sufficiently long time makes possible not only a reliable analysis of service life of surface layers on the basis of a sufficient amount of input parameters but also a design of the time schedule of repeated repairs. It can also offer to the supervisory authorities alternative solutions of surface layers taking into account their service life and financial demand. However, for any such analysis an appropriate database of material parameters is necessary.

\section{Materials}

Seven different types of plasters were investigated. Their composition is presented in Table 1 where the symbol w/ds means the water/dry substances ratio.

Table 1: $\quad$ Composition of studied plasters.

\begin{tabular}{|c|c|c|c|c|}
\hline Material & $\begin{array}{c}\text { Lime } \\
{[\mathrm{kg}]}\end{array}$ & $\begin{array}{c}\text { Pozzolan } \\
\text { [kg] }\end{array}$ & $\begin{array}{c}\text { Natural quartz and } \\
\text { basalt sand } 0 \text { to } 4 \mathrm{~mm} \\
{[\mathrm{~kg}]}\end{array}$ & $\mathrm{w} / \mathrm{ds}$ \\
\hline LMK & 1.875 & 0.625 & 7.5 & 0.27 \\
\hline LMS & 2.0 & 0.5 & 7.5 & 0.22 \\
\hline LI & 2.5 & 0 & 7.5 & 0.29 \\
\hline COM 1 & & & & 0.23 \\
\hline COM 2 & & & & 0.17 \\
\hline LCS & & & & 0.17 \\
\hline LCL & & & & 0.19 \\
\hline
\end{tabular}

Pure lime plaster LI, lime-metakaolin plaster LMK and lime-metashale plaster LMS were mixed in the laboratory according to the previous experience with this type of plasters. A CL-90 lime hydrate complying with the European standard EN 459-1 was used for the preparation of mixes. The composition of applied pozzolans is shown in Table 2. 
Table 2: $\quad$ Chemical composition of pozzolans (mass \%).

\begin{tabular}{|c|c|c|}
\hline Component & Metakaolin & Metashale \\
\hline $\mathrm{SiO}_{2}$ & 58.70 & 52.90 \\
\hline $\mathrm{Al}_{2} \mathrm{O}_{3}$ & 38.50 & 41.90 \\
\hline $\mathrm{Fe}_{2} \mathrm{O}_{3}$ & 0.72 & 1.08 \\
\hline $\mathrm{CaO}$ & 0.20 & 0.13 \\
\hline $\mathrm{MgO}$ & 0.38 & 0.18 \\
\hline $\mathrm{K}_{2} \mathrm{O}$ & 0.85 & 0.77 \\
\hline $\mathrm{TiO}_{2}$ & 0.50 & 1.80 \\
\hline
\end{tabular}

Two other studied plasters were commercial renovation renders denoted as COM 1 and COM 2. Their exact composition was not known. LCL was a limecement render with lightweight aggregate, LSC a common lime-cement plaster. Both LCL and LCS were obtained as commercially produced dry mixes.

\section{Experimental methods}

\subsection{Basic physical properties}

As fundamental physical material characteristics, bulk density [ $\mathrm{kg} \mathrm{m}^{-3}$, open porosity [Vol.-\%] and matrix density [ $\mathrm{kg} \mathrm{m}^{-3}$ ] were measured using the water vacuum saturation method [7]. In the first step, the samples were dried in a drier to remove majority of the physically bound water. After that the samples were placed into a desiccator with distilled water. During three hours air was evacuated with vacuum pump from the desiccator. The specimen was then kept under water not less than 24 hours. From the mass of water saturated sample $m_{w}$ [kg] and mass of the immersed water saturated sample $m_{a}[\mathrm{~kg}]$, the volume $\mathrm{V}$ of the sample was determined, and the basic physical properties were calculated.

Characterization of the pore structure was performed by mercury instrusion porosimetry. The experiments were carried out using the instruments PASCAL 140 and 440 (Thermo Scientific). The range of applied pressure corresponds to pore radius from $3 \mathrm{~nm}$ to $100 \mu \mathrm{m}$.

\subsection{Mechanical properties}

The flexural strength was determined after 28 days of standard curing according to ČSN EN 1015-11 [8] as a standard three-point bending test, using the MTS QTEST 100 testing machine for samples with the dimensions of $40 \times 40 \times 160 \mathrm{~mm}$. . The span length between the supports was $100 \mathrm{~mm}$. The loading rate was $0.15 \mathrm{~mm} / \mathrm{min}$. Portions of the mortar prisms tested in flexure 
were used for the determination of compressive strength as described in ČSN EN 1015-11 [8].

\subsection{Water vapor transport properties}

The dry cup method was employed in the measurements of water vapor transport parameters [7]. The sealed cups containing silica gel were placed into a controlled climatic chamber with $50 \%$ relative humidity and weighted periodically. Measurements were done at $25^{\circ} \mathrm{C}$ in the time period of two weeks. The water vapor diffusion permeability $\delta$ [s], water vapor diffusion coefficient $D$ $\left[\mathrm{m}^{2} \mathrm{~s}^{-1}\right]$ and water vapor diffusion resistance factor $\mu[-]$ were determined. The measurement was done on the samples with the dimensions of $100 \mathrm{x} 100 \mathrm{x}$ $20 \mathrm{~mm}$.

\subsection{Water transport properties}

The water absorption coefficient $A\left[\mathrm{~kg} \mathrm{~m}^{-2} \mathrm{~s}^{-1 / 2}\right]$ and apparent moisture diffusivity $\kappa\left[\mathrm{m}^{2} \mathrm{~s}^{-1}\right]$ were measured using a water sorptivity experiment $[9,10]$. The specimens were water- and vapor-proof insulated on four lateral sides and the face side was immersed 1-2 mm into water. The automatic balance allowed recording the increase of mass. The measurement was done on the samples with the dimensions of $50 \times 50 \times 20 \mathrm{~mm}$.

\subsection{Thermal properties}

Thermal conductivity $\lambda\left[\mathrm{W} \mathrm{m}{ }^{-1} \mathrm{~K}^{-1}\right]$ and specific heat capacity $c\left[\mathrm{~J} \mathrm{~kg}^{-1} \mathrm{~K}^{-1}\right]$ were measured using the commercial device ISOMET 2104 (Applied Precision, Ltd.). The measurement is based on analysis of the temperature response of the analyzed material to heat flow impulses. The heat flow is induced by electrical heating using a resistor heater having a direct thermal contact with the surface of the sample. The measurement was done on the samples with the dimensions of $70 \times 70 \times 70 \mathrm{~mm}$.

\section{Experimental results}

\subsection{Basic physical properties}

The basic physical properties of the studied materials are shown in Table 3. The highest porosity exhibited LCL with the lightweight aggregate; the second was COM1 which contained foaming admixtures. The lowest porosity exhibited LCS which was an expected outcome. The bulk densities corresponded to the measured values of open porosity.

The pore size distribution curves (Figure 1) of most plasters had similar features, with a major peak in a range of $0.6-1.2 \mu \mathrm{m}$. LCL exhibited very different pore size distribution compared to the others, with a distinct peak at $6 \mu \mathrm{m}$, COM2 contained a significant amount of pores between $10 \mu \mathrm{m}$ and $100 \mu \mathrm{m}$. This was accordance with their assumed composition. 
Table 3: $\quad$ Basic physical properties of studied plasters.

\begin{tabular}{|c|c|c|c|}
\hline \multirow{2}{*}{ Material } & $\rho$ & $\rho_{\text {mat }}$ & $\psi$ \\
\cline { 2 - 4 } & {$\left[\mathrm{kg} \mathrm{m}^{-3}\right]$} & {$\left[\mathrm{kg} \mathrm{m}^{-3}\right]$} & {$[\%]$} \\
\hline LMK & 1584 & 2574 & 38.5 \\
\hline LMS & 1741 & 2688 & 30.8 \\
\hline LI & 1805 & 2879 & 31.1 \\
\hline COM 1 & 1384 & 2609 & 47.3 \\
\hline COM 2 & 1479 & 2539 & 41.8 \\
\hline LCL & 774 & 1906 & 59.2 \\
\hline LCS & 1831 & 2577 & 27.5 \\
\hline
\end{tabular}

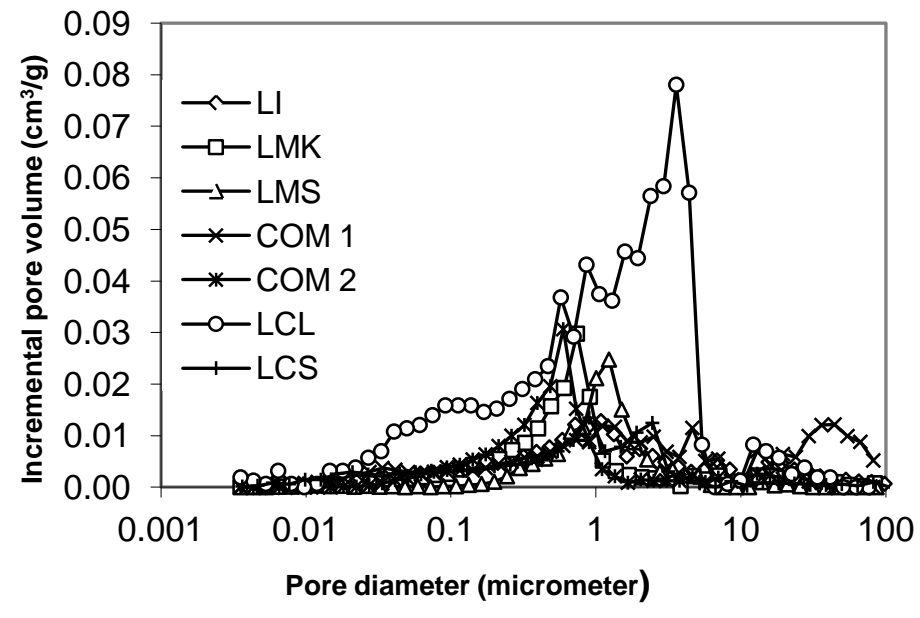

Figure 1: $\quad$ The pore size distribution of renovation plasters.

\subsection{Mechanical properties}

The best mechanical parameters (Figure 2) exhibited the lime-cement plaster LCS but the lime-pozzolana plaster LMK was not much worse. This confirmed its good prerequisites for the application in renovation of historical buildings. Commercial plasters COM 1 and COM 2 had lower strengths than LMK but higher than LMS. The plaster LCL with lightweight aggregate achieved similar strengths as the reference lime plaster. 


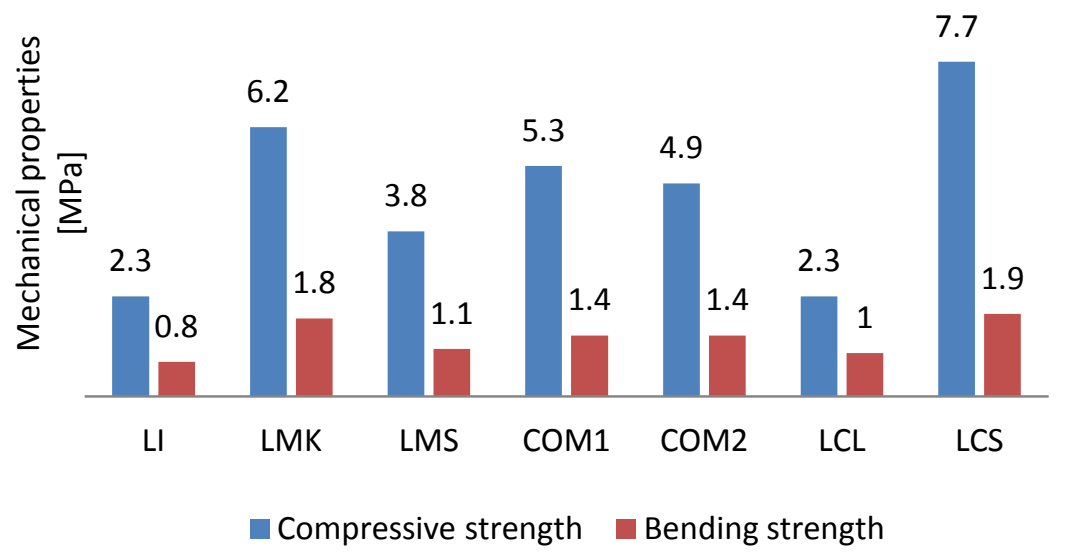

Figure 2: $\quad$ Mechanical properties of studied plasters.

\subsection{Water vapor transport properties}

Table 4 shows water vapor diffusion parameters of the analyzed materials. The lowest capability of water vapor transport exhibited LMK, the highest LCL and COM1.

Table 4: $\quad$ Water vapor transport properties of studied plasters.

\begin{tabular}{|c|c|c|c|}
\hline \multirow{2}{*}{ Material } & \multicolumn{3}{|c|}{$5 / 50 \%$} \\
\cline { 2 - 4 } & $\delta$ & $D$ & $\mu$ \\
\cline { 2 - 4 } & {$[\mathrm{s}]$} & {$\left[\mathrm{m}^{2} \mathrm{~s}^{-1}\right]$} & {$[-]$} \\
\hline LMK & $3.56 \mathrm{E}-12$ & $4.90 \mathrm{E}-07$ & 51.1 \\
\hline LMS & $9.74 \mathrm{E}-12$ & $1.34 \mathrm{E}-06$ & 17.1 \\
\hline LI & $1.11 \mathrm{E}-11$ & $1.53 \mathrm{E}-06$ & 15.0 \\
\hline COM 1 & $1.44 \mathrm{E}-11$ & $1.98 \mathrm{E}-06$ & 12.6 \\
\hline COM 2 & $7.23 \mathrm{E}-12$ & $9.93 \mathrm{E}-07$ & 23.3 \\
\hline LCL & $1.44 \mathrm{E}-11$ & $1.98 \mathrm{E}-06$ & 11.7 \\
\hline LCS & $8.63 \mathrm{E}-12$ & $1.18 \mathrm{E}-7$ & 19.4 \\
\hline
\end{tabular}

\subsection{Water transport properties}

Table 5 shows the results of water sorptivity measurement. The lowest water absorption coefficient had the commercial plaster COM1 which was not in a good agreement with its porosity value. The possible reason could be the use of hydrophobic agents for its production. The second lowest $A$ value achieved the 
lime-pozzolan plaster LMK which corresponded with its low water vapor transport capability. The reference lime plaster and the lime-cement plaster with lightweight aggregate LCL showed the highest water absorption coefficients which was an expected behavior.

Table 5: $\quad$ Water transport properties of studied plasters.

\begin{tabular}{|c|c|c|}
\hline \multirow{2}{*}{ Material } & $A$ & $\kappa$ \\
\cline { 2 - 3 } & {$\left[\mathrm{kg} \mathrm{m}^{-2} \mathrm{~s}^{-1 / 2}\right]$} & {$\left[\mathrm{m}^{2} \mathrm{~s}^{-1}\right]$} \\
\hline LMK & 0.087 & $6.69 \mathrm{E}-08$ \\
\hline LMS & 0.133 & $1.71 \mathrm{E}-07$ \\
\hline LI & 0.206 & $8.80 \mathrm{E}-07$ \\
\hline COM 1 & 0.073 & $2.41 \mathrm{E}-08$ \\
\hline COM 2 & 0.145 & $1.18 \mathrm{E}-07$ \\
\hline LCL & 0.197 & $1.35 \mathrm{E}-07$ \\
\hline LCS & 0.177 & $5.89 \mathrm{E}-07$ \\
\hline
\end{tabular}

\subsection{Thermal properties}

Thermal properties of the studied plasters in dry state are shown in Table 6 . From a qualitative point of view, they agreed with the porosity data given in Table 3. Apparently, the materials with the highest porosity, LCL and COM1 achieved the lowest thermal conductivity values. On the other hand, the highest thermal conductivity had LCS with the lowest porosity. The specific heat capacity in dry state of most plasters was similar. The only exception presented COM 2 with significantly higher $c$ value. This was probably caused by some admixtures of organic origin but this can be considered as a mere hypothesis due to the lack of information on the exact composition of commercial plasters.

Table 6: $\quad$ Thermal properties of studied plasters in dry state.

\begin{tabular}{|c|c|c|}
\hline Material & $\lambda\left[\mathrm{Wm}^{-1} \mathrm{~K}^{-1}\right]$ & $\mathrm{c}\left[\mathrm{Jkg}^{-1} \mathrm{~K}^{-1}\right]$ \\
\hline LMK & 0.499 & 902 \\
\hline LMS & 0.802 & 853 \\
\hline LI & 1.042 & 817 \\
\hline COM 1 & 0.366 & 1028 \\
\hline COM 2 & 0.464 & 1479 \\
\hline LCL & 0.167 & 994 \\
\hline LCS & 1.14 & 896 \\
\hline
\end{tabular}

Figure 3 shows a remarkable increase of thermal conductivity of all analyzed plasters with the increasing moisture content. The values in water saturated state were about 2-3 times higher than the values in dry state. 


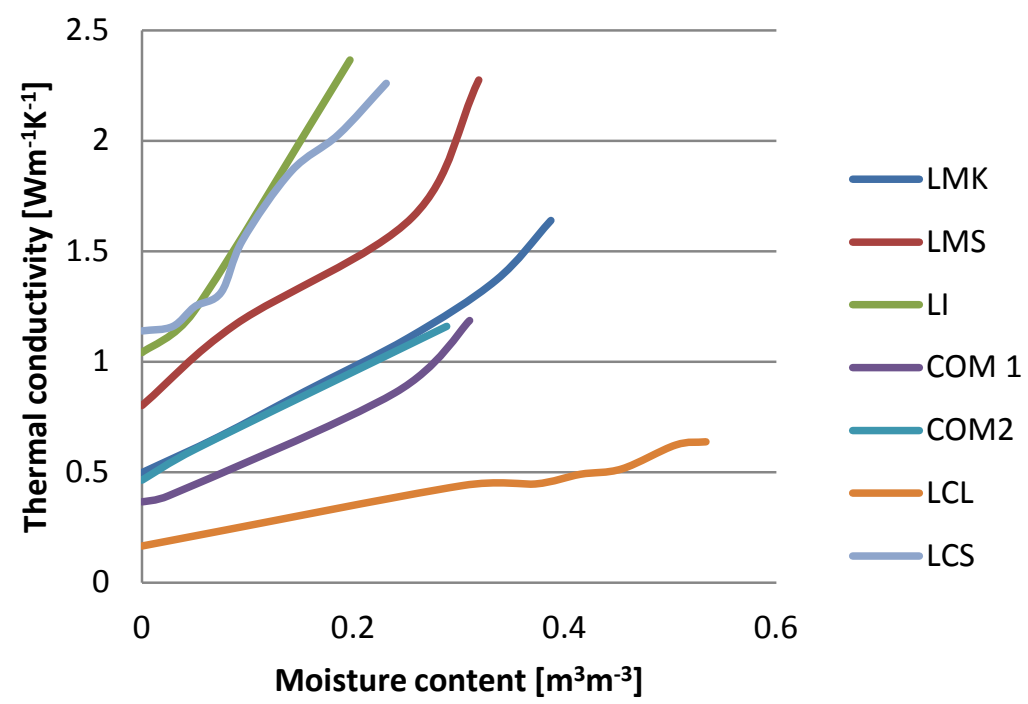

Figure 3: Thermal conductivity of studied plasters as a function of moisture content.

The specific heat capacity as a function of moisture content was calculated according to the theoretical procedure described in [11], under the assumption that this heat storage parameter is an additive quantity in the sense of the linear theory of mixtures:

$$
c_{w e t}(w)=\frac{\rho_{d r y} c_{d r y}+\rho_{w} c_{w} w}{\rho_{d r y}+\rho_{w} w}
$$

where $\rho_{\text {wet }}$ is the bulk density of the wet material, $\rho_{\text {dry }}$ the bulk density of the dry material, $\rho_{w}$ the density of water, $w$ the moisture content by volume,

$$
w=\frac{V_{w}}{V}
$$

$V_{\mathrm{w}}$ is the volume of water in the pores, $V$ is the volume of the whole specimen, $c_{\text {wet, }} c_{\text {dry }}$ and $c_{w}$ are the specific heat capacities of the wet material, the dry material and water, respectively.

The results are presented in Figure 4. Apparently, they reflect the high specific heat capacity of water as compared with the dry plasters. 


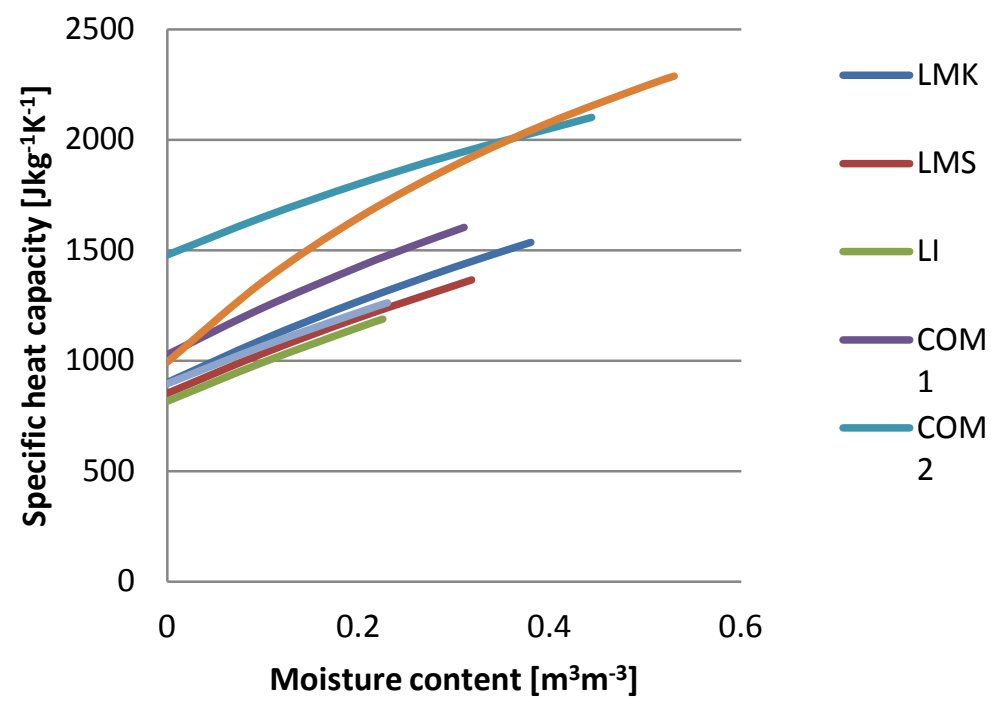

Figure 4: $\quad$ Specific heat capacity of studied plasters as a function of moisture content calculated according to Eq. (1).

\section{Conclusions}

The basic physical properties, mechanical properties, and hygric and thermal parameters of plasters suitable for application at the renovation of historical buildings, which were determined in this paper, can be used as input parameters of computational models of heat and moisture transport and mechanical damage models. This can greatly enhance the reliability of this kind of models at the service life prediction analyses. Similar measurements are, however, necessary to be performed for the materials of load bearing structures of historical buildings. Establishment of the material database including representative original materials of historical buildings and their possible replacements presents an important step towards an improvement of the current practice of reconstruction of historical buildings.

\section{Acknowledgement}

This research has been supported by the Ministry of Culture of the Czech Republic, under project No DF12P01OVV030.

\section{References}

[1] Groot, C., Repair mortars for historic masonry, Materials and Structures, 45, pp. 1277-1285, 2012. 
[2] Lindqvist J.E., Johansson, S., Sub-hydraulic binders in historic mortar, RILEM-workshop TC 203, Delft, 2005.

[3] Ashurst, J., Ashurst, N., Mortars, plasters \& renders, English heritage technical handbook, vol. 3. Aldershot, Hants: Ashgate Publishing; 2005.

[4] Cabrera, J. and Rojas, M.S., Mechanism of hydration of the metakaolinlime-water system. Cement and Concrete Research, 31, pp. 177-187, 2001.

[5] Rojas, M.S. and Cabrera, J., The effect of temperature on the hydration rate and stability of the hydration phases of metakaolin-lime-water systems. Cement and Concrete Research, 32, pp. 133-138, 2002.

[6] Vejmelková, E., Pernicová, R., Sovják, R. and Černý, R., Properties of innovative renders on lime basis for the renovation of historical buildings. Structural Studies, Repairs and Maintenance of Heritage Architecture XI, ed. C. A. Brebbia, WIT Press: Southampton, pp. 221-229, 2009.

[7] Roels, S., Carmeliet, J., Hens, H., Adan, O., Brocken, H., Černý, R., Pavlík, Z., Hall, C., Kumaran, K., Pel, L. and Plagge, R., Interlaboratory Comparison of Hygric Properties of Porous Building Materials. Journal of Thermal Envelope and Building Science, 27, pp. 307-325, 2004.

[8] ČSN EN 1015-11, Methods of test for mortar for masonry - Part 11: Determination of flexural and compressive strength of hardened mortar. Czech Standardization Institute: Prague, 2000.

[9] Kumaran, M.K., Moisture diffusivity of building materials from water absorption measurements. Journal of Thermal Envelope and Building Science, 22, pp. 349-355, 1999.

[10] Vejmelková, E., Pavlíková, M., Jerman, M. and Černý, R. Free Water Intake as Means of Material Characterization. Journal of Building Physics, 33, pp. 29-44, 2009.

[11] Jerman, M., Keppert. M., Výborný, J. and Černý, R., Moisture and heat transport and storage characteristics of two commercial autoclaved aerated concretes. Cement Wapno Beton, 16/78, pp. 18-29, 2011. 